\title{
On the behavior of several fitness functions for genetically optimized microstrip antennas
}

\author{
Jeevani Jayasinghe $^{1 *}$, Jaume Anguera ${ }^{2}$, Disala Uduwawala ${ }^{3}$ \\ ${ }^{I}$ Wayamba University of Sri Lanka, Kuliyapitiya, Sri Lanka \\ ${ }^{2}$ Universitat Ramon LLull, Barcelona, Spain \\ ${ }^{3}$ University of Peradeniya,Peradeniya, Sri Lanka \\ *Corresponding authorE-mail: jeevani@wyb.ac.lk
}

Copyright (-) 2015 Jeevani Jayasinghe et al. This is an open access article distributed under the Creative Commons Attribution License, which permits unrestricted use, distribution, and reproduction in any medium, provided the original work is properly cited.

\begin{abstract}
Genetic algorithm (GA) is a popular optimization technique used in the design of performance improved microstrip patch antennas (MPAs). The fitness function plays a vital role in the successful application of GA in MPAs. This paper investigates the performance of several fitness functions for achieving bandwidth improved MPAs.
\end{abstract}

Keywords: Broadband Antenna; Fitness; Genetic Algorithms; Microstrip Patch Antennas; Optimization.

\section{Introduction}

Among the performance improvement techniques, genetic algorithm (GA), which is a powerful optimization technique, has shown to be useful in a wide area of electromagnetics [1-4]. GA has been used to enhance the performance of microstrip patch antennas (MPAs) by optimizing the bandwidth, resonating frequency, directivity, gain, size etc. which results in non-conventional patch geometries. When there are several current paths on the patch, MPAs show multiband [5-11] performance. When such multiple resonant bands are close enough to overlap, MPAs show broadband [10-17] performance. Longer meandering current paths on the patch lead to miniature [18-20] performance. Furthermore, inphase currents result in high-directivity [21-22] MPAs. Moreover, GAO has been used to design MPAs with broadside radiation [23].

In order to improve the performance of MPAs, one or more of several parameters such as patch geometry, feed position and substrate thickness \& permittivity can be tuned using GA. The appropriate formulation of the fitness function is very important in the success of optimization procedure. It serves as the link between the physical problem being optimized and GA. Therefore, it impacts the speed of simulation, convergence rate and ability to find the optimized design, etc. If the calculation of fitness is complex and time consuming, then the simulation speed reduces. In addition, defining of a poor fitness function does not facilitate fast convergence towards the optimized design. Sometimes, the fitness function may find a good design instead of the optimized design. Therefore, it is necessary to define the fitness function carefully, in order to converge towards the optimized design.

Different fitness functions have been used by researchers to design MPAs. In some designs [1] the goal was to minimize the maximum S11 magnitude at several frequencies. Summation of reflection coefficient values over a range of frequencies is another fitness function presented in the literature [24]. In some designs [9], [13], reflection coefficient values were summed, while considering the values less than $-10 \mathrm{~dB}$ as $-10 \mathrm{~dB}$. The same method was used in [25] by considering values less than $-15 \mathrm{~dB}$ as $-15 \mathrm{~dB}$. Summation of reflection coefficient values, weighted by a half-sinusoidal function is proposed in [26]. In [11], percentage of reflected power averaged over several frequencies in the bandwidth has been assigned as the fitness. In addition to the reflection coefficient values, electric field strength normal to the patch [27], input impedances [28] and errors due to wave reflection/ transmission at the input ports [5] were also included in the fitness functions. In the present paper, several fitness functions are compared and a new one is introduced in order to obtain a broadband MPA. 
The paper is divided as follows. Section 2 explains the antenna configuration and GA optimization procedure. Section 3 illustrates four fitness functions available in the literature and introduces a novel fitness function. Five MPAs are optimized by using these fitness functions and their bandwidth performances are compared. Section 3 describes an overlapping method of cells, which simplifies the fabrication process. Finally conclusions are given.

\section{Antenna configuration and GA optimization}

An experiment is conducted to investigate a suitable fitness function to design broadband MPAs. Five fitness functions, which were maximized in the search for the optimum solution, are used in GA to optimize the performance of the MPA. The patch is etched on a substrate of Neltec NX9320 (IM) (tm), which has a relative permittivity of 3.2, a loss tangent of 0.0025 and a height of $6 \mathrm{~mm}$. The length and the width of the patch are $17.5 \mathrm{~mm}$ and $26 \mathrm{~mm}$ respectively which have been chosen so that a simple rectangular MPA resonates at $4000 \mathrm{MHz}$ in the fundamental mode. The substrate size is 40 $\times 45 \mathrm{~mm}^{2}$ on a ground plane with the same dimensions. A $50 \Omega$ coaxial cable is used to feed the antenna with the diameter of the inner conductor of the probe feed being $0.7 \mathrm{~mm}$.

The conventional rectangular MPA is narrowband operating from $3840 \mathrm{MHz}$ to $4200 \mathrm{MHz}$. Therefore, its fractional bandwidth $\left(\mathrm{S}_{11} \leq-10 \mathrm{~dB}\right)$ is $9 \%$ (figure 1$)$.

(a)

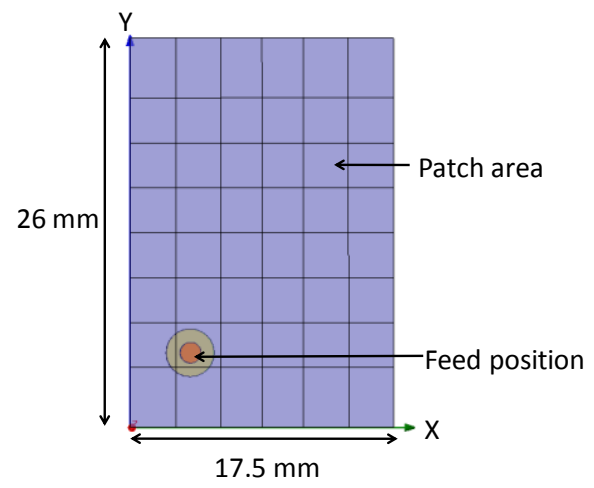

(b)

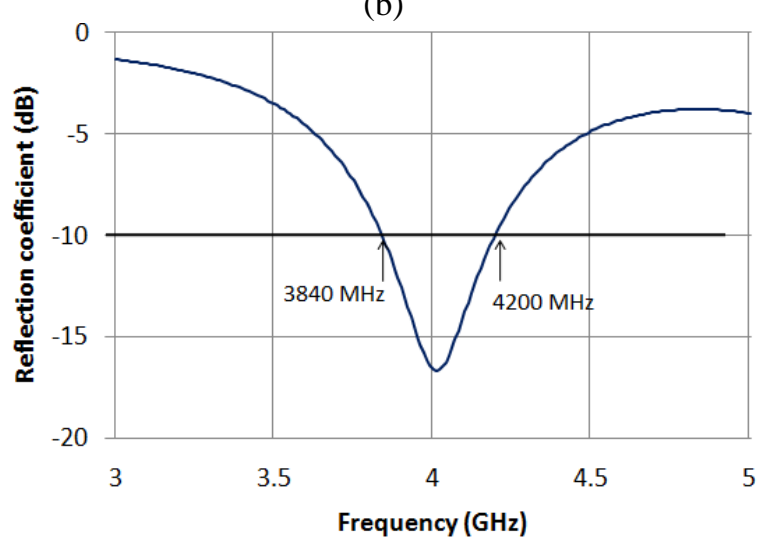

Fig. 1: Rectangular MPA. (A) Antenna Configuration Showing the 48 Cells Used for the GA. (B) $S_{11}$ Plot.

It is fragmented into 48 cells to search the best solution of conducting cells. The first 48 bits of the chromosome are used to define the patch geometry, by assigning conducting or non-conducting properties to each cell. As there are only two possible values, binary coding is used. Next five genes of the chromosome are used to define the feed position (Table 1).

Table 1: Format of the Chromosome for Genetic Patch

\begin{tabular}{ll}
\hline Patch geometry & Feed position \\
\hline $0 \ldots \ldots \ldots \ldots . .47$ & $48 \ldots \ldots \ldots \ldots . .52$ \\
\hline
\end{tabular}

The GA architecture employs 20 chromosomes per generation. Binary tournament selection method is used to select pairs of chromosomes. The crossover operation is performed with probability of $100 \%$. The probability of mutation is $1.5 \%$. GA operations are applied until the best fitness converges.

\section{Results}

\subsection{First fitness function}

The first fitness function considers the reflection coefficient in $\mathrm{dB}$ only at $4000 \mathrm{MHz}$ (equation 1). It is organized to make a maximization problem, as the reflection coefficient values are negative.

$F=-\rho\left(f_{i}\right)$,

where $\rho\left(f_{i}\right)$ is the reflection coefficient at frequency $f_{i}$.

The optimized MPA has a fractional bandwidth of $10 \%$, which is slightly larger than that of a rectangular MPA (Figure 2a). This fitness function is suitable to design an MPA with very low reflection coefficients at the resonant frequency, but it does not support to design broadband MPAs. 


\subsection{Second fitness function}

The second fitness function considers the summation of reflection coefficient values in $\mathrm{dB}$ around the resonant frequency [1], [24], which is $4000 \mathrm{MHz}$ (equation 2). In this case also, reflection coefficients are multiplied by -1 to make a maximization problem as follows:

$$
F=-\sum_{f_{i}=f_{1}}^{f_{2}} \rho\left(f_{i}\right)
$$

where frequency range is from $f_{1}$ to $f_{2}$, containing $N$ number of samples.

Initially, reflection coefficient values at two frequencies $\left(f_{1}=3750 \mathrm{MHz}\right.$ and $\left.f_{2}=4250 \mathrm{MHz}\right)$ have been considered with $N=2$. This fitness function leads to a discontinuous frequency band of operation as shown in Figure $2 \mathrm{~b}$. This is due to the large gap between the two frequencies considered. Therefore, $N=11$ has been considered, where the fitness function consists of reflection coefficient values, at every $100 \mathrm{MHz}$ between $f_{1}=3500 \mathrm{MHz}$ and $f_{2}=4500 \mathrm{MHz}$ The optimized design has a fractional bandwidth of $16 \%$ which is considerably large (Figure $2 b$ ). Results show that this fitness function also results in narrow band designs with lower reflection coefficient values, instead of broadband designs.

\subsection{Third fitness function}

The third fitness function consists of reflection coefficient values in $\mathrm{dB}$ taken at $100 \mathrm{MHz}$ intervals over the range of $1000 \mathrm{MHz}$ from $f_{1}=3500 \mathrm{MHz}$ to $f_{2}=4500 \mathrm{MHz}$ with $N=11$. In order to avoid the solutions of narrow bandwidth with very low reflection coefficient values and to increase the bandwidth as much as possible, reflection coefficient values less than $-10 \mathrm{~dB}$ are considered as $-10 \mathrm{~dB}$ [9],[13]. Therefore, the fitness function is defined as

$$
F=-\sum_{f_{i}=f_{1}}^{f_{2}} L\left(f_{i}\right)
$$

Where

$$
L\left(f_{i}\right)=\left\{\begin{array}{cl}
\rho\left(f_{i}\right) d B & \rho\left(f_{i}\right) d B \geq-10 d B \\
-10 d B & \rho\left(f_{i}\right) d B<-10 d B
\end{array} .\right.
$$

The optimized design has a bandwidth of $28 \%$ operating in the frequency range from $3510 \mathrm{MHz}$ to $4630 \mathrm{MHz}$ (Figure 2c).

\subsection{Fourth fitness function}

The fourth fitness function consists of reflection coefficient values in $\mathrm{dB}$ obtained at $100 \mathrm{MHz}$ frequency steps in the frequency range from $f_{1}=3500 \mathrm{MHz}$ to $f_{2}=4500 \mathrm{MHz}$, weighted by a half sinusoidal function [26] (equation 5).

$$
F=-\sum_{f_{i}=f_{1}}^{f_{2}} \rho\left(f_{i}\right) \sin \frac{\pi(f-3.4)}{1.2}
$$

The optimized design has a bandwidth of $21 \%$ operating in the frequency range from $3470 \mathrm{MHz}$ to $4270 \mathrm{MHz}$ (Figure 2d).

\subsection{Fifth fitness function}

Another fitness function is defined to avoid the solutions of narrow bandwidth with very low reflection coefficient values and to increase the bandwidth as much as possible. In this case also, the fitness function is defined by summing the magnitudes of the reflection coefficient $\rho$ taken at $100 \mathrm{MHz}$ intervals over the range of $1000 \mathrm{MHz}$, by forcing reflection coefficients between $-10 \mathrm{~dB}$ and $-15 \mathrm{DB}$. Therefore, the fitness function is defined as

$$
L\left(f_{i}\right)=\left\{\begin{array}{cc}
\rho\left(f_{i}\right) & \rho\left(f_{i}\right) \geq-10 d B \\
-15 d B & -15 d B \leq \rho\left(f_{i}\right)<-10 d B \\
-30 d B-\rho\left(f_{i}\right) & -30 d B \leq \rho\left(f_{i}\right)<-15 d B \\
0 & \rho\left(f_{i}\right)<-30 d B
\end{array}\right.
$$

The optimized design has a bandwidth of $33 \%$ operating in the frequency range from $3630 \mathrm{MHz}$ to $5080 \mathrm{MHz}$ (Figure3). 
(a)

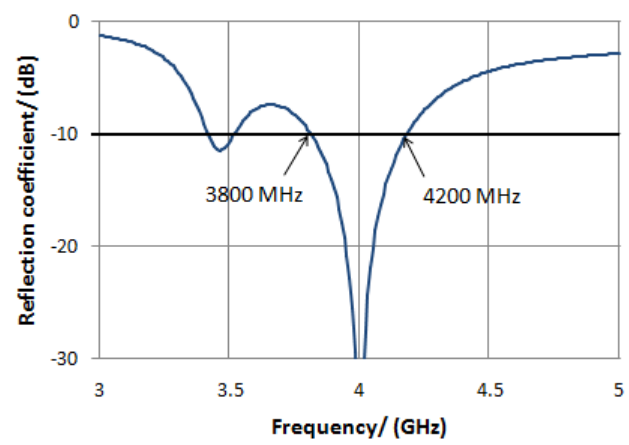

(c)

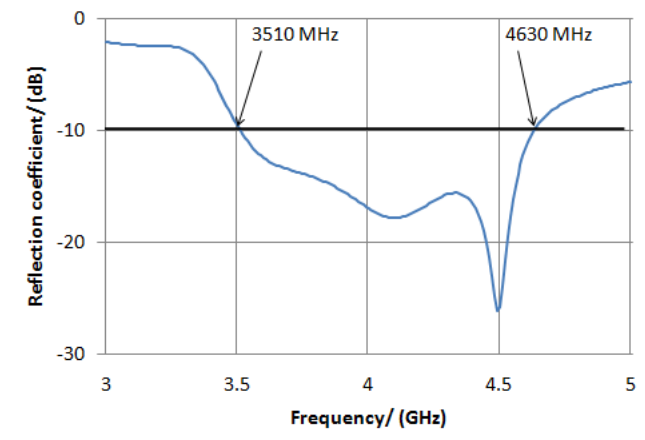

(b)

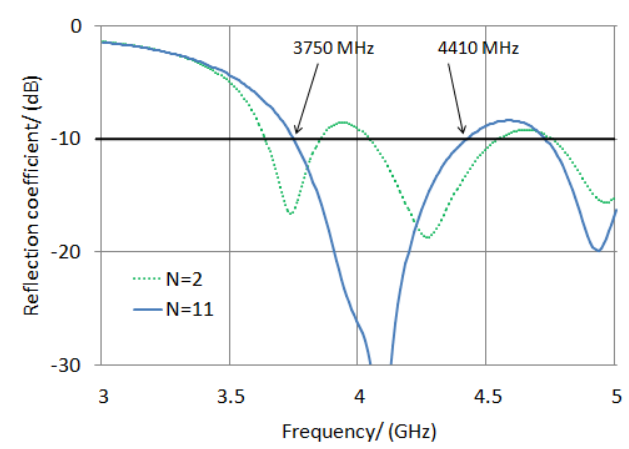

(d)

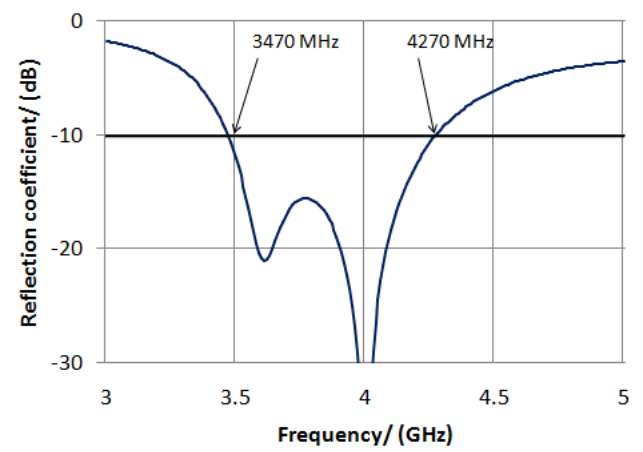

Fig. 2: $\mathrm{S}_{11}$ Plots of the Optimized Designs for Different Fitness Functions. (A) For the First Fitness Function. (B) For the Second Fitness Function. (C) For the Third Fitness Function. (D) For the Forth Fitness Function.

(a)

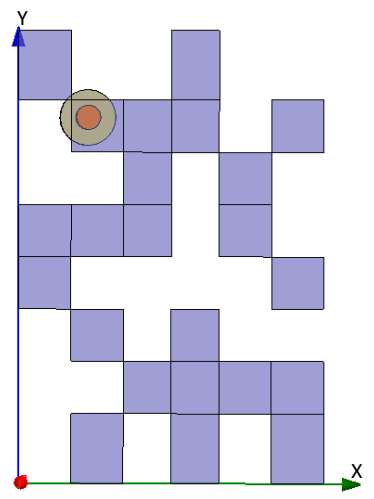

(b)

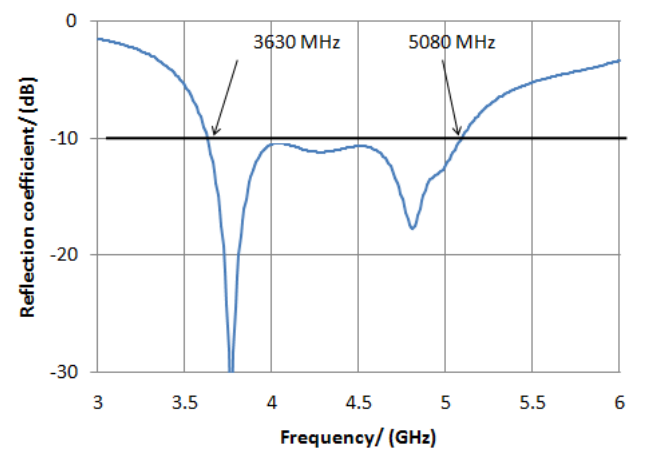

Fig. 3: Optimized Design for the Fifth Fitness Function. (A) Patch Geometry. (B) $S_{11}$ Plot.

The results are summarized in Table 2. According to the results, the best fitness function to design broadband MPAs is the fifth fitness function. It can be modified as

$F=-\left(\sum_{f_{i}=f_{1}}^{f_{2}} L\left(f_{i}\right)+\sum_{f_{i}=f_{3}}^{f_{4}} L\left(f_{i}\right)+\ldots \ldots.\right)$

where $f_{1}$ to $f_{2}, f_{3}$ to $f_{4}$ and so on are the required frequency bands to design multiband MPAs which operate in two or more frequency bands. 
Table 2: Fitness Function vs. Bandwidth Performance of Optimized MPAs

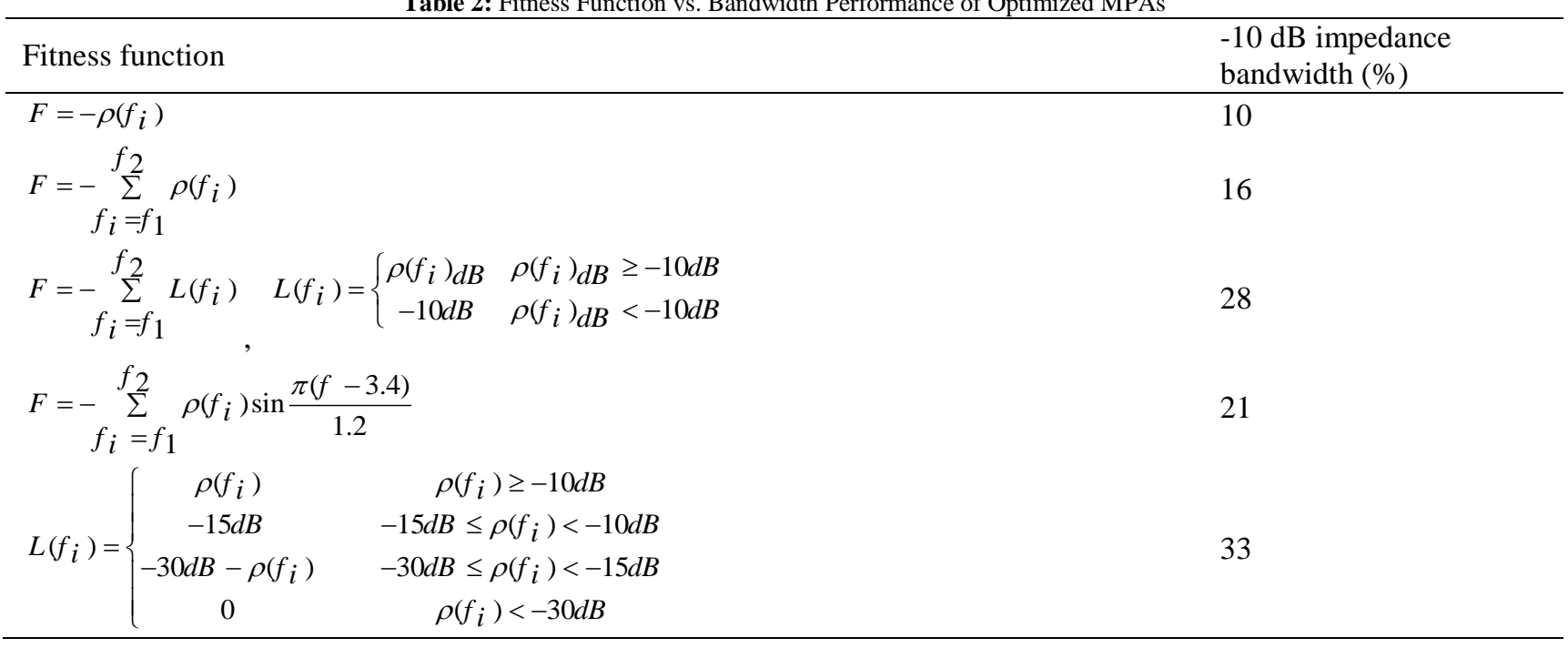

\section{Practical considerations}

The traditional method of using on/off building blocks to make cells contact each other by infinitesimal points may pose a connection problem, when manufacturing the MPA, due to the tolerances of chemical etching [9, 26]. To avoid having cells contacting each other by infinitesimal points, an overlapping based on a shifting of cells along the vertical axis is proposed in combination with the best fitness function. This technique simplifies the fabrication of MPAs obtained through GA optimization.

The optimized design obtained by using the best fitness function with overlapping cells is shown in Figure 4 . In addition to advantages in fabrication process, this design improves the bandwidth too. The optimized design has a bandwidth of $35 \%$ operating in the frequency range from $3490 \mathrm{MHz}$ to $4950 \mathrm{MHz}$.

(a)

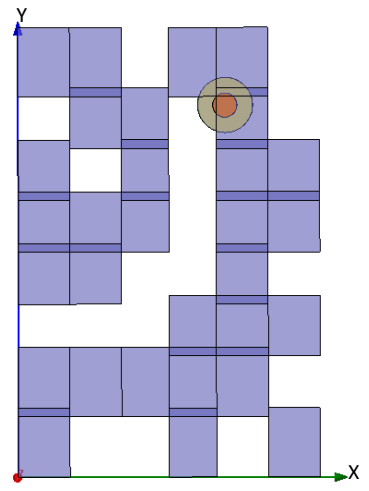

(b)

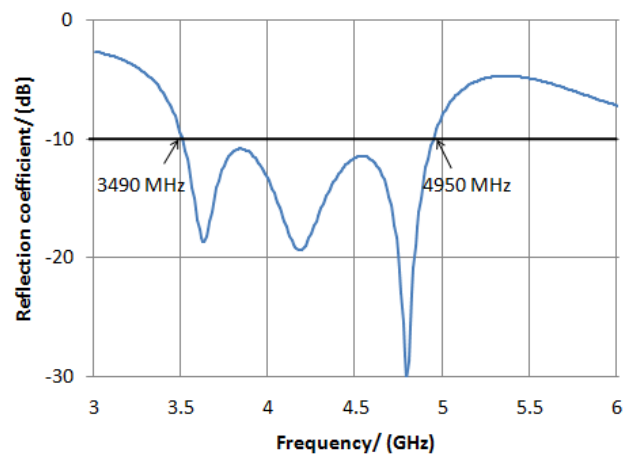

Fig. 4: Optimized Design with Overlapping Cells. (A) Patch Geometry. (B) $S_{11}$ Plot.

\section{Conclusions}

Five different fitness functions have been considered for obtaining bandwidth optimized MPAs. The last of the five fitness functions proposed in the paper obtains a fractional bandwidth of $35 \%$. This has been achieved by tuning only the patch geometry and feed position in the optimization. The bandwidth could be further improved by including other parameters such as substrate properties as well.

\section{References}

[1] Johnson, J.M. and Rahmat-Samii, Y., "Genetic Algorithms in Engineering Electromagnetics", IEEE Transactions on Antennas and Propagation, Vol. 39, (1997), pp.7-21. http://dx.doi.org/10.1109/74.632992.

[2] Johnson, J.M. and Rahmat-Samii, Y., "Genetic algorithms and method of moments (GA/MOM) for the design of integrated antennas", IEEE Transactions on Antennas and Propagation, Vol. 47, No.10, (1997), pp.1606-1614. http://dx.doi.org/10.1109/8.805906.

[3] O'Donnell, T.H., Altshuler, E.E. and Best, S.R., "The significance of genetic representation in genetic antenna design", Antennas and Propagation Society International Symposium, Vol.1, (2003), pp.149-152. 
[4] Weile, D.S. and Michielssen, E., "Genetic algorithm optimization applied to electromagnetics: A review", IEEE Transactions on Antennas and Propagation, Vol.45, No.3, (1997), pp.343-353. http://dx.doi.org/10.1109/8.558650.

[5] Villegas, F.J., Cwik, T., Rahmat-Samii Y. and Manteghi, M., "A parallel Electromagnetic genetic-Algorithm optimization application for patch antenna design", IEEE Transactions on Antennas and Propagation, Vol.52, (2004), pp.2424-2435. http://dx.doi.org/10.1109/TAP.2004.834071.

[6] Ohira, M., Deguchi, H., Tsuji, M. and Shigesawa, H., "Multiband single-layer frequency selective surface designed by combination of genetic algorithm and geometry-refinement technique", IEEE Transactions on Antennas and Propagation, Vol.52, No. 11, (2004), pp.2925- 2931. http://dx.doi.org/10.1109/TAP.2004.835289.

[7] Sathi, V., Taherizadeh, S., Lotfi, A. and Ghobadi, C., "Optimization of multi-frequency microstrip antenna using genetic algorithm coupled with method of moments" Microwaves, Antennas \& Propagation, IET , Vol.4, No. 4, (2010), pp.477-483. http://dx.doi.org/10.1049/ietmap.2009.0020.

[8] Lotfi, A.A. and Kashani, F.H., "Bandwidth optimization of the E-shaped microstrip antenna using the genetic algorithm based on fuzzy decision making", Antennas and Propagation Society International Symposium, Vol.3, (2004), 2333-2336.

[9] Jayasinghe, J.W., Anguera, J. and Uduwawala, D.N., "A simple design of multi band microstrip patch antennas robust to fabrication tolerances for GSM, UMTS, LTE, and Bluetooth applications by using genetic algorithm optimization", Progress In Electromagnetics Research M., Vol.27 (2012), pp.255-269. http://dx.doi.org/10.2528/PIERM12102705.

[10] Spence, T.G., Werner, D.H. and Groff, R.D., "Genetic algorithm optimization of some novel broadband and multiband microstrip antennas", Antennas and Propagation Society International Symposium, Vol.4, (2004), pp.4408-4411.

[11] Griffiths, L.A., Furse C. and Chung, Y.C., "Broadband and multiband antenna design using the genetic algorithm to create amorphous shapes using ellipses", IEEE Transactions on Antennas and Propagation, Vol.54, No.10, (2006), pp.2776-2782. http://dx.doi.org/10.1109/TAP.2006.882154.

[12] Telzhensky, N. and Leviatan, Y., "Novel method of UWB antenna optimization for specified input signal forms by means of genetic algorithm", IEEE Transactions on Antennas and Propagation, Vol. 54, No.8, (2006), pp.2216-2225. http://dx.doi.org/10.1109/TAP.2006.879201.

[13] Jayasinghe, J.M.J.W. and D.N. Uduwawala, "Design of Broadband Patch Antennas using Genetic Algorithm Optimization", 5th International Conference on Industrial and Information Systems, 2010, pp.60-65. http://dx.doi.org/10.1109/ICIINFS.2010.5578733

[14] Choo, H., Hutani, A., Trintinalia, L.C. and Ling, H., "Shape optimisation of broadband microstrip antennas using genetic algorithm", Electronics Letter, Vol. 36, No. 25, (2000), pp. 2057-2058. http://dx.doi.org/10.1049/el:20001452.

[15] Sun, S., Yinghua, L.V. and Zhang, J., "The Application of Genetic Algorithm Optimization in Broadband Microstrip antenna Design", Antennas and Propagation Society International Symposium, (2010), pp. 1-4.

[16] Jayasinghe, J.M.J.W. and Uduwawala, D.N., "Optimization of the performance of patch antennas using genetic algorithms", Journal of National Science Foundation, Vol. 41, No.2, (2013), pp.115-122. http://dx.doi.org/10.4038/jnsfsr.v41i2.5705

[17] Michael, K. and Kucharski, A.A., "Genetic Algorithm Optimization for Broadband Patch Antenna Design", International Conference on Microwaves, Radar \& Wireless Communications, (2006), pp.748-751.

[18] Soontornpipit, P., Furse C.M. and Chung, Y. C., "Miniaturized biocompatible microstrip antenna using genetic algorithms", IEEE Transactions on Antennas and Propagation, Vol.53, No.6, (2005), pp.1939-1945. http://dx.doi.org/10.1109/TAP.2005.848461.

[19] Herscovici, N., Osorio, M.F. and Peixeiro, C., "Miniaturization of rectangular microstrip patches using genetic algorithms", IEEE Antennas and wireless propagation letters, (2002), Vol.1, pp.94-97. http://dx.doi.org/10.1109/LAWP.2002.805128.

[20] Jayasinghe, J.M.J.W., D.N. Uduwawala, "A Novel Miniature Multi-Frequency Broadband Patch Antenna for WLAN Applications", 8th IEEE International Conference on Industrial and Information Systems, (2013), pp.361-363. http://dx.doi.org/10.1109/ICIInfS.2013.6732010

[21] Jayasinghe, J.M.J.W., Anguera, J. and Uduwawala, D.N., "Genetic algorithm optimization of a high-directivity microstrip patch antenna having a rectangular profile", Radioengineering, Vol.22, No. 3, (2013), pp.700-707.

[22] Jayasinghe, J.W., Anguera, J. and Uduwawala, D.N., "A high-directivity microstrip patch antenna design by using genetic algorithm optimization", Progress In Electromagnetics Research C, Vol. 37, (2013), pp.131-144. http://dx.doi.org/10.2528/PIERC13010805.

[23] Jayasinghe, J.M.J.W., D.N. Uduwawala, and J. Anguera, "Design of a genetic microstrip patch antenna with broadside radiation for GSM applications", International Journal of Scientific World, Vol. 2, No. 2, (2014), pp.84-87. http://dx.doi.org/10.14419/ijsw.v2i2.3703.

[24] Sun, S., Yinghua, L.V. and Zhang, J., "The Application of Genetic Algorithm Optimization in Broadband Microstrip antenna Design", Antennas and Propagation Society International Symposium, (2010), pp. 1-4.

[25] Chouksey, S., M. Ghadle, "A genetic Algorithm for Optimization of Microstrip Patch Antenna", International Journal of Electrical, Electronics and Computer Engineering, Vol. 1, No.2, (2012), pp. 97- 99.

[26] Thors, B., Steyskal, H. and Holter, H., "Broadband fragmented aperture phased array element design using genetic algorithms", IEEE trans Antennas propagate, Vol.53, No.10, (2005), pp.3280-3287.

[27] Polivka, M., Drahovzal M., Rohan J. and Hazdra P., "Multiband patch antenna with perturbation elements generated by genetic algorithm" Proceedings of European Conference on Antennas and Propagation, (2006), pp.6-10.

[28] Ozgun, O. et al. "Design of dual-frequency probe-fed microstrip antennas with genetic optimization algorithm", IEEE Transactions on Antennas and Propagation, Vol. 51, No.8, (2003), pp.1947-1954. http://dx.doi.org/10.1109/TAP.2003.814732. 